\title{
Artificial weathering and accelerated heat aging studies on low-density polyethylene (LDPE) produced via autoclave and tubular process technologies
}

\author{
A. S. Luyt ${ }^{1}$, S. A. Gasmi ${ }^{1}$, S. S. Malik ${ }^{1}$, R. M. Aljindi ${ }^{2}$, M. Ouederni ${ }^{3}$, S. N. Vouyiouka ${ }^{4}$, \\ A. D. Porfyris $^{4}$, R. Pfaendner ${ }^{5}$, C. D. Papaspyrides ${ }^{4}$ \\ ${ }^{1}$ Center for Advanced Materials, Qatar University, P.O. Box 2713, Doha, Qatar \\ ${ }^{2}$ Department of Mechanical \& Industrial Engineering, College of Engineering, Qatar University, P.O. Box 2713, Doha, \\ Qatar \\ ${ }^{3}$ Qatar Petrochemical Company (QAPCO), P.O. Box 756, Doha, Qatar \\ ${ }^{4}$ Laboratory of Polymer Technology, School of Chemical Engineering, National Technical University of Athens, \\ Zographou Campus, 15780 Athens, Greece \\ ${ }^{5}$ Fraunhofer Institute for Structural Durability and System Reliability LBF, Schlossgartenstr. 6, 64289 Darmstadt, \\ Germany
}

Received 17 May 2020; accepted in revised form 3 July 2020

\begin{abstract}
Accelerated (artificial) weathering and thermal aging tests were performed to investigate the effectiveness of different formulations in reducing the UV/heat degradation extent for two low-density polyethylene types (LDPE-A, LDPE-T). The two LDPEs differ in the type and extent of branching due to the applied polymerization process, with LDPE-A being produced in an autoclave and LDPE-T in a tubular reactor. Oligomeric or high molecular weight hindered amine light stabilizer (HALS), and two UV absorbers of benzophenone or hydroxyphenyl-triazine types were equally introduced to both the LDPE grades at a total content of $0.2 \mathrm{wt} \%$. The surface morphology, as well as thermal and mechanical properties, were examined during aging showing a significant degradation extent for the neat samples. In particular, a mechanism of chain scission/branching that resulted in crosslinking was assumed for the neat polyethylenes, after combining the decrease of molecular weight observed in the GPC analysis with the increase in Young's modulus after UV exposure. LDPE-T presented higher photo-oxidation rates due to its comb-like branched structure and its higher possibility of intermolecular reactions between adjacent chains. Little or no degradation was observed for the stabilized grades, confirming the effectiveness of the selected UV/heat systems in improving the weathering resistance of the two LDPE grades and enhancing their useful lifetime.
\end{abstract}

Keywords: processing technologies, low-density polyethylene, degradation, UV/heat stabilization

\section{Introduction}

With the excessive use of polyolefins in commercial and industrial sectors, polyolefins, specifically polyethylenes (P.E.s), have received substantial attention and became a fundamental topic of research. Their demand has been reported to increase globally, and the current estimated production is well in excess of 100 million tons. Due to their unique and outstanding properties such as their toughness and flexibility, even at low temperatures, excellent chemical resistance, easy processability, no odor and toxicity, and their low cost, P.E.s have been widely used for numerous applications such as packaging, buildings, electrical fittings, and agricultural piping [1]. However, P.E.s like all organic materials suffer from poor weathering resistance under the influence of the different 
environmental factors such as heat, moisture, solar radiation, weather pollutants, and ultraviolet radiation [2], leading to an inevitable degradation which limits their service lifetime and severely restricts their performance for outdoor applications [3].

Photodegradation of polymers is a combination of the oxidative effect of atmospheric oxygen with the photochemical and photophysical effects of ultraviolet radiation photons. The combined effect of oxygen and light radiation induces a complex set of processes that can cause undesirable changes in the appearance of the polymer's surface, such as discoloration, embrittlement, tackiness, loss of surface gloss, and crazing or chalking of the surface [4]. It is a combination of thermal and UV induced degradation, following the same mechanism of free radical release, crosslinking, and then loss of properties [5, 6].

The development of highly effective UV stabilization systems is crucial in the polyethylene industry. UV absorbers, amongst the most commonly used photostabilizers, protect the polymer from photo-oxidation by absorbing the harmful UV radiation during the first step of the photo-oxidation process and preventing its interaction with the photoactive chromophoric species in the polymer molecule [7]. Hindered amine light stabilizers (HALS), which are also long-term thermal stabilizers, have the ability to scavenge radicals created by UV absorption during the photo-oxidation processes or during heat aging by forming nitroxyl radicals through a cyclic mechanism known as the Denisov Cycle, and hence restricting the photodegradation process. HALS are considered as one of the best and most efficient groups of UV stabilizers for most polyolefins, and all commercial products share the 2,2,6,6-tetramethylpiperidine ring structure.

The current work focused on the UV/heat stabilization of low-density polyethylene (LDPE), considering that nowadays, two different LDPE grades are produced in Qatar and widely used. In particular, autoclave (batch process) and tubular (continuous process) reactor technologies are currently employed in the production of LDPE at high pressures and temperatures in the presence of specific chemical initiators via free radical reaction mechanisms [8]. A number of works already exist on the differences in molecular architecture between these two LDPE grades as well as on modeling the relevant processes in an autoclave and tubular reactors $[9,10]$. The main differences are the level and type of long-chain branching, as well as their molecular shape. LDPE-A is produced at constant pressure in well-stirred autoclave vessels under practically ideal backmixing, and presents broad molecular weight distributions with a bias towards the low molecular weight end. It is thus characterized by a tree-like chain branching, distributed essentially at random along the chains, an approximately globular molecular shape in dilute solutions, and lower tensile strength. On the other hand, LDPE-T is produced in a very long and small diameter tubular reactor through a continuous tubular process (low level of backmixing, varied pressure) [1], shows a narrower molecular weight distribution with a bias towards the high molecular weight end. LDPE-T molecules are characterized by comblike branching, linear molecular shapes (rod-like) in solutions, and higher tensile strength [9-12]. Apart from branching, LDPE molecules contain other imperfections, for instance, double bonds. Vinyl $\left(-\mathrm{CH}=\mathrm{CH}_{2}\right)$ and vinylidene $(-\mathrm{CH}=\mathrm{CH}-)$ double bonds may arise from disproportionation and $\beta$-scission reactions. The concentration of such double bonds is generally less than $0.1 \%$ of all the carboncarbon bonds [12], while decomposition reactions occur less frequently in tubular processes due to a higher cooling surface area than in the autoclave reactor [11]. The latter can explain the higher number of vinylene per thousand carbons in LDPE-A $(\sim 0.84$ groups $/ 1000)$ compared to LDPE-T ( $\sim 0.47$ groups $/ 1000)$ [13].

Several studies investigated the weathering of different polyolefins combined with different HALS through natural (outdoor) or accelerated (artificial) modes [14-22]. More specifically, the synergistic effect of HALS and UV absorbers for stabilizing LDPE films was examined [14], where films containing a combination of HALS and UV absorbers retained $50 \%$ of their tensile strength after 590 days, whereas films containing only HALS reached the same value after only 205 days. The UV stability of the LDPE films was also found to be significantly improved by combining a HALS, i.e., Chimassorb 2020 with a UV absorber, i.e., Tinuvin 1577 [17]. The high molecular weight HALS was found to be effective for polyolefins not only as a UV stabilizer, but also as a longterm thermal stabilizer [16, 19-22]. Several studies proved that an oligomeric HALS such as Chimassorb 944 is efficient as a UV and thermal stabilizer for LLDPE and LDPE films [16, 20, 22]. It was reported that Chimassorb 944 was successful in reducing the 
carbonyl index, which is considered as one of the main indicators of photodegradation [18]. The efficiency of HALS as a free radical scavenger during photooxidation processes was also studied and reported through multiple weathering studies [14, 16, 22].

Most published weathering studies examined the UV and thermal stability of one P.E. type and grade. However, in this study, we compared the effectiveness of different UV absorbers/HALS formulations in the two different LDPEs (LDPE-A, LDPE-T) with different structures as a result of different production methods, something that to the best of our knowledge has not previously been published in the open literature. The herein examined formulations had equal loadings of UV absorber ( $0.1 \mathrm{wt} \%$, benzophenone, and hydroxyphenyl-triazine types) and oligomeric or high molecular HALS $(0.1 \mathrm{wt} \%)$ for both LDPE grades, while samples were exposed to accelerated weathering in a weatherometer and accelerated aging in a forced-air oven. The surface morphology, as well as thermal and mechanical properties determined through tensile and impact testing, gel permeation chromatography (GPC), scanning electron microscopy (SEM), Fourier transform infrared (FTIR) spectroscopy, differential scanning calorimetry (DSC), and thermogravimetric analysis (TGA), served to monitor the efficiency of the UV/heat stabilization systems.

\section{Materials and methods}

\subsection{Materials}

Two commercial low-density polyethylene (LDPE) grades (LDPE-A and LDPE-T) were provided by Qatar Petrochemical Company (QAPCO, Doha,

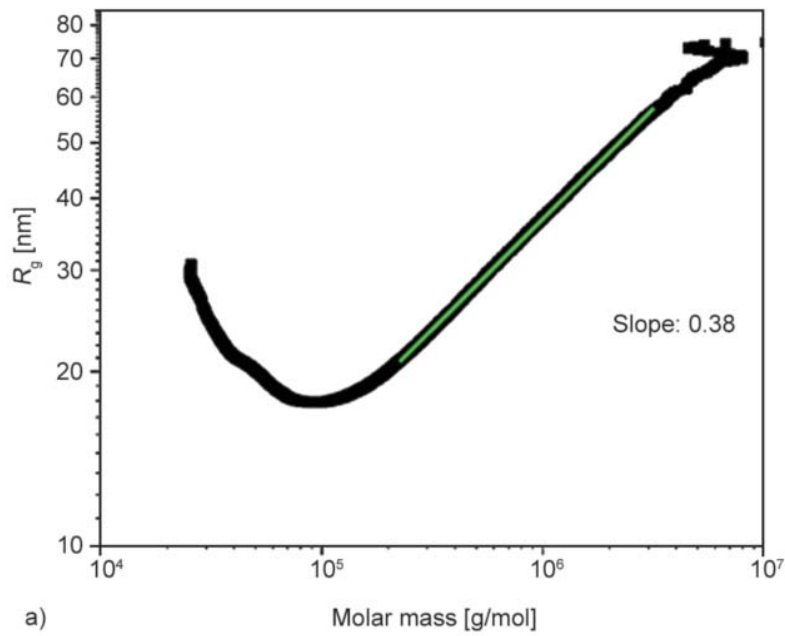

Qatar). LDPE-A (density $=920 \mathrm{~kg} \cdot \mathrm{m}^{-3}, \mathrm{MFI}=$ $0.3 \mathrm{~g} / 10 \mathrm{~min}, T_{\mathrm{m}}=109^{\circ} \mathrm{C}$ ) refers to an LDPE manufactured in an autoclave (batch process) and LDPE-T $\left(\right.$ density $=923 \mathrm{~kg} \cdot \mathrm{m}^{-3}$, MFI $=0.3 \mathrm{~g} / 10 \mathrm{~min}, T_{\mathrm{m}}=$ $112^{\circ} \mathrm{C}$ ) to an LDPE manufactured in a tubular reactor (continuous process). Both polymers were received as pellets and were cryogenically milled down into powder by Weaver Trading Company in South Africa.

The weight average molar masses and distributions of the samples were characterized by gel permeation chromatography with multi-angle laser light scattering (HT-GPC-MALS) and found to be $M_{\mathrm{w}}=$ $364 \mathrm{~kg} \cdot \mathrm{mol}^{-1} / M_{\mathrm{n}}=26 \mathrm{~kg} \cdot \mathrm{mol}^{-1}\left(\right.$ LDPE-A) and $M_{\mathrm{w}}=$ $240 \mathrm{~kg} \cdot \mathrm{mol}^{-1} / M_{\mathrm{n}}=26 \mathrm{~kg} \cdot \mathrm{mol}^{-1}$ (LDPE-T). Their long-chain branching (LCB) content was similarly characterized and LDPE-A was found to contain significantly more LCB than LDPE-T. This is evident from the plots of the radius of gyration $\left(R_{\mathrm{g}}\right)$ of the samples as a function of molar mass (conformation plots) shown in Figure 1. The conformation plot for a linear polymer shows a slope of about 0.57 , and with increasing LCB content, smaller slopes are found as the molecules become more globular-shaped, which was the case of LDPE-A (slope 0.38).

Poly[[6-[(1,1,3,3-tetramethylbutyl)amino]-1,3,5-triazine-2,4-diyl][(2,2,6,6-tetramethyl-4-piperidinyl) imino]-1,6-hexanediyl[(2,2,6,6-tetramethyl-4piperidinyl)imino]] (Chimassorb 944), [2-hydroxy4-(octyloxy)phenyl]phenyl-methanone (Chimassorb 81), and 2-(4,6-Diphenyl-1,3,5-triazin-2-yl)-5-hexyloxyphenol (Tinuvin 1577) were all supplied by BASF as HALS and UV absorbers. Poly[[6-[(1,1,3,3tetramethylbutyl)amino]-1,3,5-triazine-2,4-diyl]

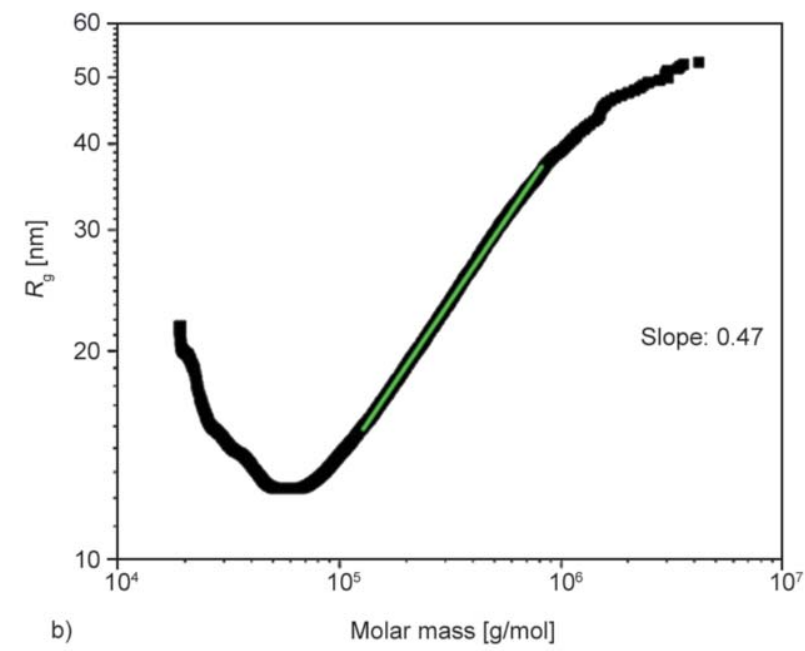

Figure 1. Conformation plot for (a) LDPE-A and (b) LDPE-T. The green line is a linear fit of the data. 
[(2,2,6,6-tetramethyl-4-piperidinyl)imino]-1,6-hexanediyl[(2,2,6,6-tetramethyl-4-piperidinyl)imino]] (Sabostab 119) was supplied by Sabo as a HALS. Calcium stearate was supplied by Scientific Global Lab Supplies W.L.L., and $0.05 \mathrm{wt} \%$ was added to the stabilized polymer systems as lubricant and acid scavenger.

\subsection{Compounding and sample preparation}

The UV/heat stabilization systems contained a total of $0.2 \mathrm{wt} \%$ additives (Table 1). The incorporation of the additives was first carried out through a thorough $20 \mathrm{~min}$. bag-mixing of the specified amounts of powdered LDPEs and the selected additives.

A twin-screw extruder KETSE 20/40 EC (Model no. 838106) was then used to melt extrude the polymer/ additive powder mixtures at a speed of $90 \mathrm{rpm}$ and with zone temperatures of $175-185-180-175-170^{\circ} \mathrm{C}$ from the feed hopper to die, and through using water at room temperature for cooling. The extruded mixture was then pelletized to ensure a smooth injection molding process. Impact and tensile specimens were prepared by injection molding using an ARBURG All-Rounder $570 \mathrm{C}$ injection molding machine, across a $180-215^{\circ} \mathrm{C}$ temperature range. The impact testing samples were produced with dimensions of $63.5 \mathrm{~mm}$ long $\times 12.7 \mathrm{~mm}$ wide $\times 3 \mathrm{~mm}$ thick (ASTM D256 standard), while the tensile testing samples were injection molded as dumbbell-shaped specimens with dimensions of $160 \mathrm{~mm}$ long $\times 13 \mathrm{~mm}$ wide (at the neck) $\times 3 \mathrm{~mm}$ thick (ISO 527 standard). The as-received neat polymer granules (without any stabilizers) were directly injection-molded but characterized following the same procedures.

\subsection{UV- and heat-exposure conditions}

The artificially simulated (accelerated) weathering was carried out in a QUV-se machine equipped with solar eye irradiance control and a UV-A lamp. The testing program was set according to the ISO 4892-3 standard, and the conditions were chosen in accordance with Qatar's climatic conditions. The $3 \mathrm{~mm}$ thick samples were exposed to repetitive cycles of UV exposure and condensation. UV radiation was set for 8 hours with an irradiance level of $0.76 \mathrm{~W} \cdot \mathrm{m}^{-2}$ at a wavelength of $340 \mathrm{~nm}$. The maximum temperature used was $60^{\circ} \mathrm{C}$ and the condensation was applied for 4 hours at a temperature of $50^{\circ} \mathrm{C}$. Samples were collected after $0,1000,1500$ and 2000 hours in the weatherometer for both LDPE-A and LDPE-T. All the samples were turned around after each $250 \mathrm{~h}$ to ensure equal UV exposure on both sample sides. It should be realized that the actual UV exposure time during the quoted times was shorter $(67 \%$ of respectively 1000,1500 and $2000 \mathrm{~h}$ ), although in this paper the terms 'weathering time' and 'UV exposure time' are used interchangeably as being the total time the respective samples spent in the weatherometer.

The thermal aging of the tensile and impact testing samples was done in an air circulating oven at $100^{\circ} \mathrm{C}$, with sampling times of $1,2,3,4,6,8,10$ and 12 months. At each sampling time, 4 specimens were removed from the oven and characterized.

\subsection{Sample characterization}

The molar mass distributions (MMD) of the samples were determined by HT-SEC. The measurements were performed in a PL 220 high-temperature size exclusion chromatograph (Polymer Laboratories, Church Stretton, UK). The temperature of the autosampler and the column compartment was set to $150^{\circ} \mathrm{C}$. A mobile phase flow rate of $1 \mathrm{ml} \cdot \mathrm{min}^{-1}$ was used. The polymer samples were dissolved for $4 \mathrm{~h}$ in TCB (containing $1 \mathrm{~g} \cdot 1^{-1}$ butylated hydroxytoluene as a stabilizer) at $160^{\circ} \mathrm{C}$. A sample concentration of $2 \mathrm{~g} \cdot \mathrm{l}^{-1}$ was used. $200 \mu \mathrm{l}$ of polymer solution was injected per analysis. Each sample was analyzed twice, and the results were averaged. A guard column (PLgel Olexis, $50 \times 7.5 \mathrm{~mm}(L \times I . D$. $))$ and three analytical columns $(3 \times$ PLgel Olexis, $300 \times 7.5 \mathrm{~mm}$ $(L \times I . D$. $)$, with particle size $13 \mu \mathrm{m}$, Agilent, Waldbronn, Germany)) were used for separation. An infrared detector (IR4, PolymerChar, Valencia, Spain) was used for detection. Data were collected and processed using WinGPC-software (version 7) from PSS (Mainz, Germany). Molar masses were calibrated with polystyrene (P.S.) standards (Polymer Standards Services, PSS, Mainz, Germany).

Table 1. Compositions of UV formulations [wt \%]. All the formulations contained $0.05 \mathrm{wt} \%$ calcium stearate.

\begin{tabular}{|l|c|c|c|c|c|}
\hline \multirow{2}{*}{} & \multirow{2}{*}{ LDPE } & Chimassorb 81 & Chimassorb 944 & Sabostab 119 & Tinuvin 1577 \\
\cline { 3 - 6 } & & UV absorber & HALS & HALS & UV absorber \\
\hline UV1 & 99.75 & 0.1 & 0.1 & & 0.1 \\
\hline UV2 & 99.75 & & & 0.1 & 0.1 \\
\hline
\end{tabular}


Scanning electron microscopy (SEM) was performed on the surfaces of the dumbbell specimens, before and after tensile testing, in an FEI Quanta 200 electron microscope (Thermo Fischer Scientific, Hillsboro, USA) at an accelerating voltage of $2-5 \mathrm{kV}$. The samples were sputter gold coated for $30 \mathrm{~s}$ using an Agar sputter coater.

Fourier transform infrared (FTIR) spectra were obtained at room temperature using a PerkinElmer Frontier Spectrum 400 FTIR spectrometer connected to a MIRACLE ATR detector with a ZnSe crystal. Sixteen scans in the range of $4000-550 \mathrm{~cm}^{-1}$ were done on each sample. The apparent degree of degradation was characterized by using a carbonyl index (CI) defined as the ratio of the maximum transmittance in the carbonyl, $\mathrm{C}=\mathrm{O}$, stretching vibration band around $1710-1730 \mathrm{~cm}^{-1}$ to that of the methylene, $\left(\mathrm{CH}_{2}\right)$, scissoring band absorption around 1300 $1400 \mathrm{~cm}^{-1}$, using Equation (1) [23]:

$C I=$

$=\frac{\text { Transmittance of carbonyl species }}{1710-1730 \mathrm{~cm}^{-1}}$

Non-isothermal crystallization analysis was performed in a Perkin Elmer DSC8500 differential scanning calorimeter under nitrogen atmosphere. Samples (5-10 mg) were sealed in aluminum sample pans and were initially heated from 30 to $180^{\circ} \mathrm{C}$ at $20^{\circ} \mathrm{C} \cdot \mathrm{min}^{-1}$ ( $1^{\text {st }}$ heating), cooled to $30^{\circ} \mathrm{C}$ at the same rate, and re-heated to $180^{\circ} \mathrm{C}$ at the same rate $\left(2^{\text {nd }}\right.$ heating). The melting enthalpy $\left(\Delta H_{\mathrm{m}}\right)$ and the peak temperature of melting $\left(T_{\mathrm{m}}\right)$ were obtained from the melting peaks in the first and second heating curves, while the crystallization temperature $(T \mathrm{c})$ and the crystallization enthalpy $\left(\Delta H_{\mathrm{c}}\right)$ were obtained from the crystallization peak in the cooling curve.

Thermal decomposition was studied via thermogravimetric analysis in a PerkinElmer TGA-4000 TGA/DSC instrument. Approximately 7-9 mg of sample was heated from 30 to $600^{\circ} \mathrm{C}$ at a heating rate of $20^{\circ} \mathrm{C} \cdot \mathrm{min}^{-1}$ under nitrogen atmosphere. The onset of decomposition temperature was defined as the temperature at $5 \%$ weight loss $\left(T_{\mathrm{d}, 5 \%}\right)$, and the temperature at the maximum rate of decomposition $\left(T_{\mathrm{d}}\right)$ was the temperature at the maximum of the peak in the derivative TGA curve.

The tensile properties were measured using a 'Lloyd LR50K plus' universal tester according to the ISO
527 standard, where no pre-load was applied to the sample. An elongation speed of $10 \mathrm{~mm} \cdot \mathrm{min}^{-1}$ and a gauge length of $50 \mathrm{~mm}$ were used. The Young's modulus $(E)$ was manually calculated from the slope of the stress-strain curve between strain values of 0.2 and $2.2 \%$. A minimum of five specimens were tested for each sample. The impact properties of the samples were investigated using an Instron Wolpert PW5 impact tester, according to ASTM D256. Specimens with dimensions of $63.5 \mathrm{~mm} \times 12.7 \mathrm{~mm} \times 3 \mathrm{~mm}$ were notched at the center $\left(45^{\circ}\right.$ notch and $2 \mathrm{~mm}$ depth). The Izod impact strength $\left[\mathrm{kJ} \cdot \mathrm{m}^{-2}\right]$ was calculated according to Equation 2 [24]:

$a_{\mathrm{iN}}=\frac{E_{\mathrm{c}}}{h \cdot b_{\mathrm{N}}}$

where $E_{\mathrm{c}}[\mathrm{J}]$ is the corrected measured absorbed energy during impact, $h[\mathrm{~mm}]$ is the thickness of the tested specimen, and $b_{\mathrm{N}}[\mathrm{mm}$ is the remaining width of the tested specimen].

\section{Results and discussion \\ 3.1. Scanning electron microscopy (SEM)}

The surface morphology of the neat and stabilized samples before and after UV exposure was firstly studied through SEM analysis since due to the low diffusion coefficient of oxygen in most polymers, degradation is generally more severe at the outer surface of the polymer than in its bulk [4]. The samples became more yellow with increasing exposure time, and significant degradation with many cracks was observed for both the neat LDPE-A and LDPE-T after $2000 \mathrm{~h} \mathrm{UV}$ exposure (Figure 2a, 2d).

The samples were also examined before and after tensile testing to investigate the effect of tensile forces on the developed of cracks under UV exposure. The crack size increased for both polymers after tensile testing (images not shown because of journal restriction on the number of images), but not significantly. The most probable reason is that the cracks did not penetrate deep enough into the relatively thick sample during the duration of the UV exposure, and that the non-degraded part of the samples below the cracks to some extent maintained the sample integrity. The situation was very different for all the stabilized samples, where much better surface integrity and almost no cracks were observed, even after long UV-exposure periods (Figure 2b, 2c, 2e, $2 \mathrm{f})$. This is a good indication that the additives were effective in protecting the samples from UV-initiated 

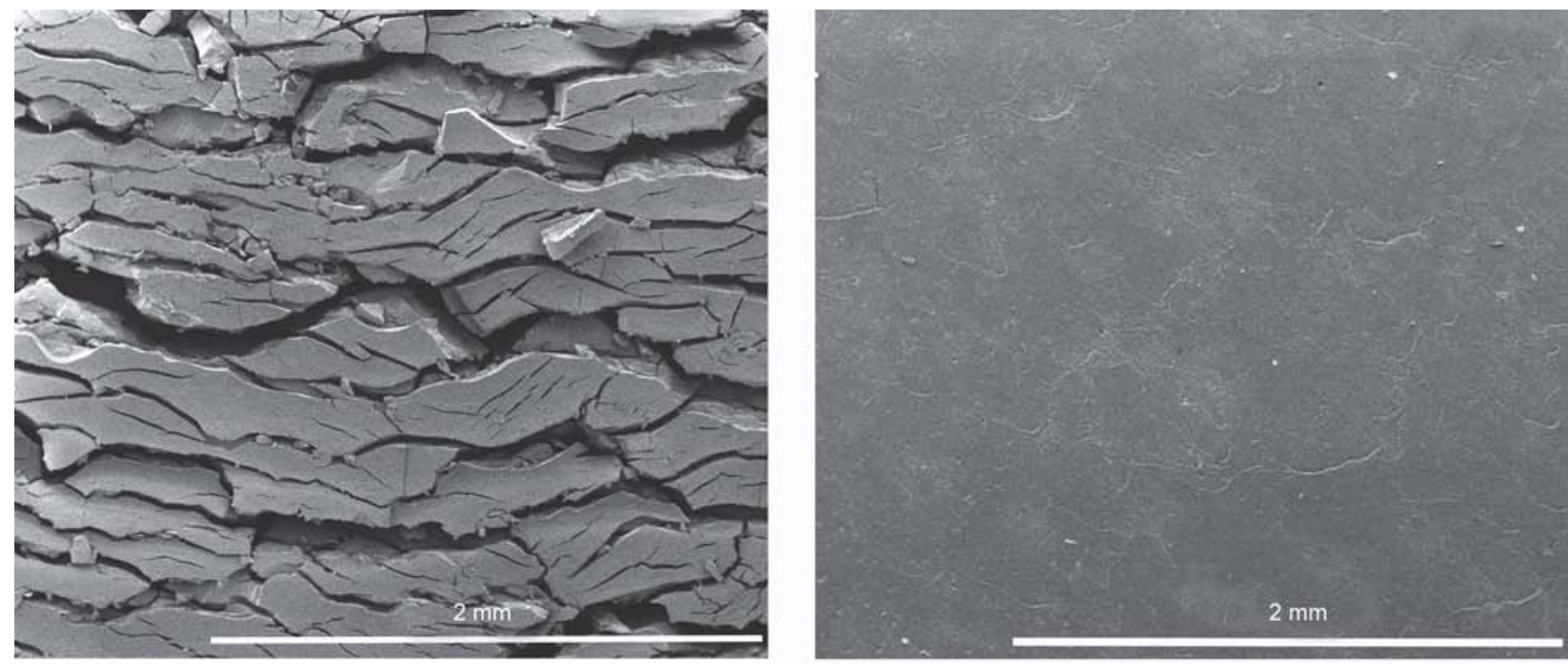

a)

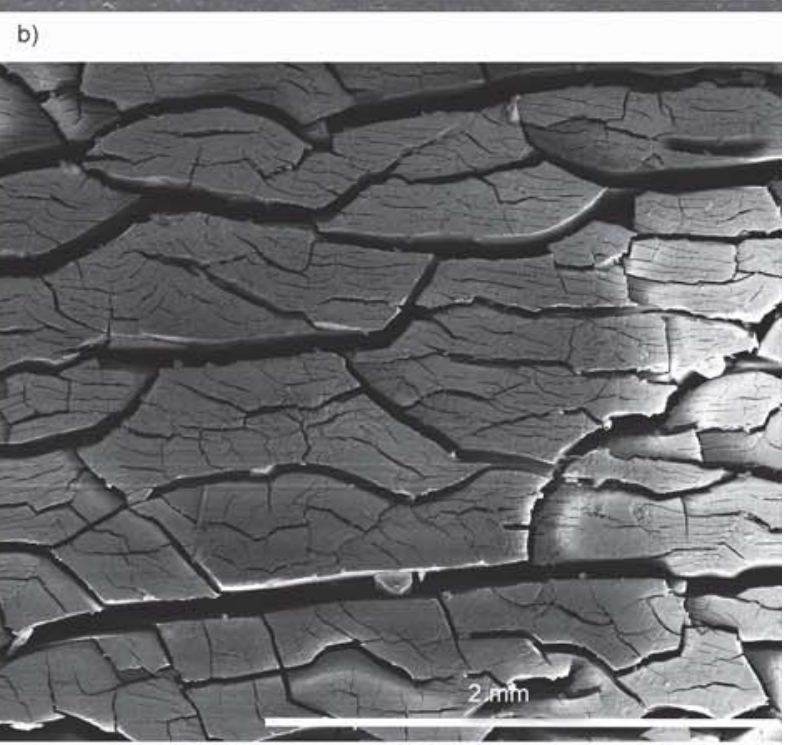

d)

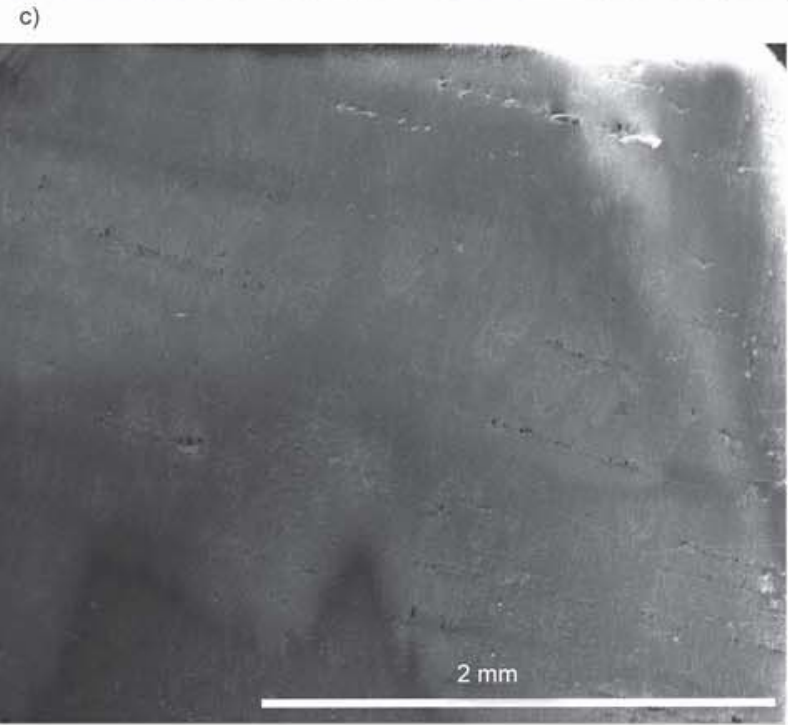

7

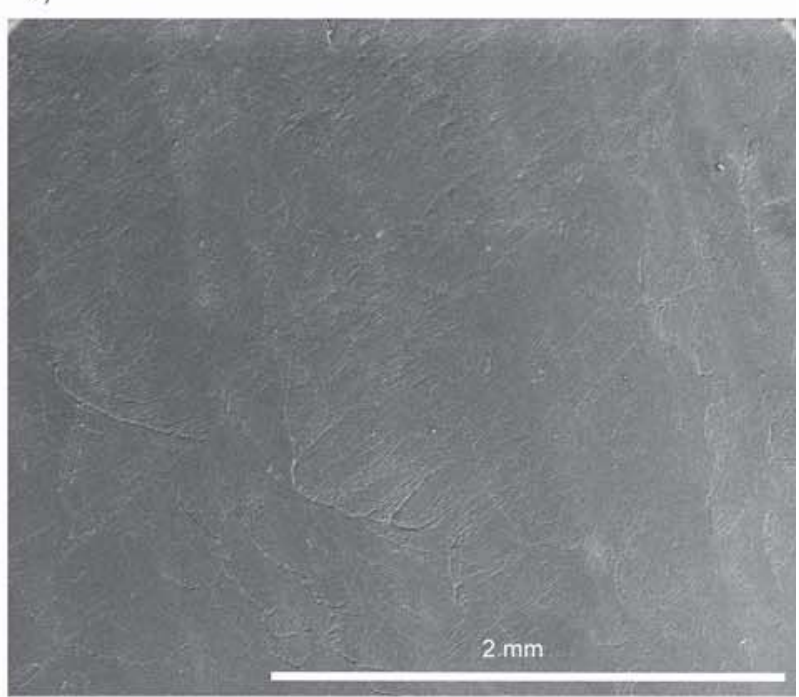

f)

Figure 2. SEM images of (a) neat LDPE-A (2000 h exposed), (b) LDPE-A/UV1 (2000 h exposed), (c) LDPE-A/UV2 (2000 h exposed), (d) neat LDPE-T (2000 h exposed), (e) LDPE-T/UV1 (2000 h exposed), and (f) LDPE-T/UV2 (2000 h exposed). 
degradation, independent of the type of LDPE investigated.

\subsection{Molecular weight (M.W.) determination}

Photochemical and thermal oxidation include migration, propagation, chain branching, and termination steps and is polymer-specific [25]. Simultaneous chain scission/chain branching leads to the crosslinking characteristic of polyethylene [13]. Gel permeation chromatography (GPC) was therefore used to observe changes in the M.W. and M.W. distribution of the investigated samples as a function of UV exposure time (Tables 2 and 3).

After the first $1000 \mathrm{~h}$ of UV exposure of the neat LDPE-A and LDPE-T, a significant decrease in average molecular weight was observed for both polymers, followed by a slight further decrease after longer UV exposure periods. Since LDPE is known to undergo crosslinking during UV initiated degradation [13], the determined low M.W. values were from the initially cleaved part of the polymer, the amount of which did not change significantly with increasing exposure time. As far as the UV/heat stabilized compounds of both polymers are concerned, it was found that the molecular weight of the UV exposed samples changed insignificantly compared to the unexposed grades, confirming the effectiveness of protecting both formulations against UV radiation via restricting crosslinking reactions and permitting proper sample dissolution and characterization.

\subsection{Mechanical properties \\ 3.3.1. Tensile testing}

First of all, the tensile properties of all the compounds, i.e., neat and UV/heat stabilized, were determined prior to any aging (Table 4), so as to check the effect of the additives on the mechanical behavior.

Table 2. Molecular weight and dispersity as a function of exposure time for all the investigated LDPE-A samples.

\begin{tabular}{|c|c|c|c|}
\hline Sample & $\begin{array}{c}M_{\mathrm{n}} \\
{\left[\mathrm{g} \cdot \mathrm{mol}^{-1}\right]}\end{array}$ & $\begin{array}{c}M_{\mathrm{w}} \\
{\left[\mathrm{g} \cdot \mathrm{mol}^{-1}\right]}\end{array}$ & $D$ \\
\hline Neat LDPE-A (unexposed) & $29764 \pm 2441$ & $345085 \pm 4137$ & $12 \pm 1$ \\
\hline LDPE-A/UV3 (unexposed) & $27062 \pm 3886$ & $447215 \pm 20131$ & $17 \pm 2$ \\
\hline LDPE-A/UV8 (unexposed) & $32238 \pm 1505$ & $441985 \pm 14347$ & $14 \pm 1$ \\
\hline Neat LDPE-A (1000 h UV exposed) & $1436 \pm 78$ & $38325 \pm 495$ & $27 \pm 2$ \\
\hline LDPE-A/UV3 (1000 h UV exposed) & $22281 \pm 1271$ & $405020 \pm 12629$ & $18 \pm 1$ \\
\hline LDPE-A/UV8 (1000 h UV exposed) & $30921 \pm 1718$ & $427635 \pm 7884$ & $14 \pm 1$ \\
\hline Neat LDPE-A (1500 h UV exposed) & $493 \pm 127$ & $50983 \pm 34044$ & $98 \pm 44$ \\
\hline LDPE-A/UV3 (1500 h UV exposed) & $23143 \pm 922$ & $373975 \pm 5112$ & $16 \pm 0$ \\
\hline LDPE-A/UV8 (1500 h UV exposed) & $29799 \pm 1547$ & $437715 \pm 827$ & $15 \pm 1$ \\
\hline Neat LDPE-A (2000 h UV exposed) & $922 \pm 1016$ & $32783 \pm 17539$ & $64 \pm 51$ \\
\hline LDPE-A/UV3 (2000 h UV exposed) & $\mathrm{z} 22562 \pm 2122$ & $314285 \pm 19099$ & $14 \pm 1$ \\
\hline LDPE-A/UV8 (2000 h UV exposed) & $25970 \pm 1462$ & $416665 \pm 4151$ & $16 \pm 1$ \\
\hline
\end{tabular}

Table 3. Molecular weight and dispersity as a function of exposure time for all the investigated LDPE-T samples.

\begin{tabular}{|l|c|c|c|}
\hline \multicolumn{1}{|c|}{ Sample } & $\begin{array}{c}\boldsymbol{M}_{\mathbf{n}} \\
{\left[\mathbf{g} \cdot \mathbf{m o l}^{-\mathbf{1}} \mathbf{l}\right.}\end{array}$ & $\begin{array}{c}\boldsymbol{M}_{\mathbf{w}} \\
{\left[\mathbf{g} \cdot \mathbf{m o l}^{-\mathbf{1}}\right]}\end{array}$ & $\boldsymbol{D}$ \\
\hline Neat LDPE-T (unexposed) & $29715 \pm 1093 \mathrm{~T}$ & $312385 \pm 7686$ & $11 \pm 0$ \\
\hline LDPE-T/UV3 (unexposed) & $33002 \pm 674$ & $297505 \pm 4094$ & $10 \pm 0$ \\
\hline LDPE-T/UV8 (unexposed) & $28716 \pm 689$ & $293885 \pm 5650$ & $18 \pm 4$ \\
\hline Neat LDPE-T (1000 $\mathrm{h}$ UV exposed) & $2205 \pm 123$ & $38275 \pm 6430$ & $10 \pm 2$ \\
\hline LDPE-T/UV3 (1000 $\mathrm{h}$ UV exposed) & $34362 \pm 5330$ & $320915 \pm 8973$ & $10 \pm 0$ \\
\hline LDPE-T/UV8 (1000 $\mathrm{h}$ UV exposed) & $30548 \pm 127$ & $296540 \pm 1810$ & $17 \pm 1$ \\
\hline Neat LDPE-T (1500 $\mathrm{h}$ UV exposed) & $2961 \pm 810$ & $50404 \pm 10625$ & $9 \pm 1$ \\
\hline LDPE-T/UV3 (1500 $\mathrm{h}$ UV exposed) & $28929 \pm 2481$ & $338735 \pm 12990$ & $70 \pm 29$ \\
\hline LDPE-T/UV8 (1500 $\mathrm{h}$ UV exposed) & $32721 \pm 2943$ & $294390 \pm 11158$ & $10 \pm 0$ \\
\hline \hline Neat LDPE-T (2000 $\mathrm{h}$ UV exposed) & $27146 \pm 1945$ & $264855 \pm 11533$ & $10 \pm 1$ \\
\hline LDPE-T/UV3 (2000 $\mathrm{h}$ UV exposed) & $31016 \pm 1369$ & $296510 \pm 5671$ & \\
\hline LDPE-T/UV8 (2000 $\mathrm{h}$ UV exposed) & & & \\
\hline
\end{tabular}


Table 4. Tensile testing results for all the investigated LDPE-A and LDPE-T samples (UV exposure).

\begin{tabular}{|c|c|c|c|}
\hline Sample & $\begin{array}{c}E \\
{[\mathrm{MPa}]}\end{array}$ & $\begin{array}{c}\sigma \\
{[\mathrm{MPa}]}\end{array}$ & $\begin{array}{c}\varepsilon \\
{[\%]}\end{array}$ \\
\hline \multicolumn{4}{|c|}{ LDPE-A } \\
\hline Neat LDPE-A (unexposed) & $122 \pm 12$ & $17.3 \pm 0.4$ & $135 \pm 8$ \\
\hline LDPE-A/UV1 (unexposed) & $143 \pm 10$ & $19.5 \pm 0.2$ & $134 \pm 3$ \\
\hline LDPE-A/UV2 (unexposed) & $133 \pm 5$ & $18.1 \pm 0.2$ & $145 \pm 6$ \\
\hline Neat LDPE-A (1000 h UV exposed) & $297 \pm 24$ & $9.7 \pm 0.3$ & $37.3 \pm 9.1$ \\
\hline LDPE-A/UV1 (1000 h UV exposed) & $146 \pm 5$ & $20.7 \pm 0.4$ & $143 \pm 7$ \\
\hline LDPE-A/UV2 (1000 h UV exposed) & $139 \pm 4$ & $18.9 \pm 0.8$ & $140 \pm 2$ \\
\hline Neat LDPE-A (1500 h UV exposed) & $336 \pm 49$ & $8.5 \pm 0.3$ & $24.1 \pm 1.3$ \\
\hline LDPE-A/UV1 (1500 h UV exposed) & $142 \pm 5$ & $20.2 \pm 0.2$ & $140 \pm 3$ \\
\hline LDPE-A/UV2 (1500 h UV exposed) & $129 \pm 6$ & $18.5 \pm 0.5$ & $139 \pm 7$ \\
\hline Neat LDPE-A (2000 h UV exposed) & $289 \pm 37$ & $6.6 \pm 0.7$ & $21.1 \pm 2.0$ \\
\hline LDPE-A/UV1 (2000 h UV exposed) & $155 \pm 12$ & $20.7 \pm 0.6$ & $151 \pm 6$ \\
\hline LDPE-A/UV2 (2000 h UV exposed) & $132 \pm 12$ & $17.7 \pm 0.6$ & $140 \pm 4$ \\
\hline \multicolumn{4}{|c|}{ LDPE-T } \\
\hline Neat LDPE-T (unexposed) & $128 \pm 5$ & $17.8 \pm 0.2$ & $130 \pm 3$ \\
\hline LDPE-T/UV1 (unexposed) & $144 \pm 12$ & $17.3 \pm 1.8$ & $154 \pm 23$ \\
\hline LDPE-T/UV2 (unexposed) & $138 \pm 10$ & $17.1 \pm 0.3$ & $139 \pm 8$ \\
\hline Neat LDPE-T (1000 h UV exposed) & $346 \pm 110$ & $7.9 \pm 0.8$ & $25.6 \pm 5.0$ \\
\hline LDPE-T/UV1 (1000 h UV exposed) & $155 \pm 10$ & $17.5 \pm 0.4$ & $144 \pm 4$ \\
\hline LDPE-T/UV2 (1000 h UV exposed) & $133 \pm 18$ & $16.8 \pm 0.4$ & $143 \pm 7$ \\
\hline Neat LDPE-T (1500 h UV exposed) & $388 \pm 97$ & $6.9 \pm 0.9$ & $27.7 \pm 8.2$ \\
\hline LDPE-T/UV1 (1500 h UV exposed) & $134 \pm 19$ & $15.2 \pm 3.5$ & $139 \pm 13$ \\
\hline LDPE-T/UV2 (1500 h UV exposed) & $155 \pm 4$ & $17.2 \pm 0.8$ & $140 \pm 6$ \\
\hline Neat LDPE-T (2000 h UV exposed) & $354 \pm 102$ & $5.9 \pm 1.1$ & $23.0 \pm 7.8$ \\
\hline LDPE-T/UV1 (2000 h UV exposed) & $160 \pm 14$ & $15.9 \pm 1.2$ & $131 \pm 15$ \\
\hline LDPE-T/UV2 (2000 h UV exposed) & $152 \pm 16$ & $17.1 \pm 0.9$ & $139 \pm 5$ \\
\hline
\end{tabular}

Regarding the LDPE-A compounds, the incorporation of the UV/heat additives resulted in slightly increasing the tensile strength $(\sigma)$ values by $\sim 13$ and $\sim 5 \%$ for UV1 and UV2 respectively, along with a similar slight increase in Young's modulus values $(E)$, indicating that the incorporation of only $0.2 \mathrm{wt} \%$ additives renders the materials slightly tougher. The elongation $(\varepsilon)$ values were found very similar to those of the neat polymer. As far as the LDPE-T compounds are concerned, it seems that the effect of the incorporation of the additive was less significant, since the $\sigma$ values are very similar for all the compounds, with a variation of less than $4 \%$, and the $E$ values within the standard deviation. Finally, all the tensile properties seem similar for the two neat polymers, with the LDPE-T exhibiting a slightly tougher character, in accordance with the literature [26].

Regarding the tensile testing of the UV-aged samples (Table 4), neat LDPE-A showed increased Young's modulus values with increasing UV exposure time, reaching an increase of more than 130\% after $2000 \mathrm{~h}$. For both the LDPE grades, $E$ increased extensively up to $1000 \mathrm{~h} \mathrm{UV}$ exposure, after which it did not change significantly within experimental error. This increasing trend in $E$ corresponds to the formation of crosslinked structures in both LDPE grades, while it is further favored by the simultaneously increased crystallinity observed after the first $1000 \mathrm{~h}$ based on the DSC data in section 3.4.2: the UV initiated degradation started with chain scission reactions, and recrystallization of the shorter chains was favored [27]. The crosslinking during degradation mechanism is also confirmed by the trend in the tensile strength and the elongation at break: both values decreased significantly during the first $1000 \mathrm{~h}$ of UV exposure, whereafter they showed only slight further decreases, or almost no decrease in the case of elongation at break, with increasing UV exposure time (Table 4).

For the LDPE-T samples, the overall behavior was more pronounced, with higher Young's modulus values (an increase of more than 170\% after $2000 \mathrm{~h}$ ) and higher $E$ errors, thus suggesting higher degradation rates and/or higher crystallinities. These more intense phenomena in LDPE-T can be correlated to its 
linear molecular shape. Zimmering et al. [13] studied the LDPE photodecomposition, and they found that very small quantities of ethylene gas were released due to the rupture of the terminal double bond of the branch when the polyethylenes were exposed to a very low power mercury lamp (photo-exposure). When comparing LDPE-A to LDPE-T, the quantity of the ethylene gas released was higher in the case of LDPE-T, despite the higher concentration of double bonds in LDPE-A. Some authors claimed that the tree-like (helical) structure of LDPE-A [9] favors intramolecular reactions (methyl groups of the branch with other methyl or methylene groups of the chain), and restricts photodegradation due to sterical hindrance, while in the rod-like LDPE-T the possibility of intermolecular interactions with adjacent chains is dominant, i.e., the further the terminal bond is from the main chain, the higher the rates of double bond rupture and the more ethylene is released.
A totally different behavior was observed in the UV/heat stabilized compounds of LDPE-A and LDPE-T. The change in Young's modulus as a function of UV exposure time was negligible, and the values remained approximately the same with increasing UV exposure time. This indicates that degradation was absent during the UV exposure of these samples, which proves the effectiveness of the additives in protecting the LDPEs from UV initiated degradation. Moreover, there was almost no change in the tensile strength and elongation at break of both the UV1 and UV2 stabilized LDPEs with increasing UV exposure time, and very little difference between the quantitative values of these two properties for the two different polymers. This is a further confirmation of the effectiveness of the formulations used to UV stabilize the LDPEs.

We also performed heat aging, and monitored the changes in tensile properties (Table 5). As a general

Table 5. Tensile testing results for all the investigated LDPE-A and LDPE-T samples (heat exposure).

\begin{tabular}{|c|c|c|c|}
\hline Sample & $\begin{array}{c}E \\
{[\mathrm{MPa}]}\end{array}$ & $\begin{array}{c}\sigma \\
{[\mathrm{MPa}]}\end{array}$ & $\begin{array}{c}\varepsilon \\
{[\%]}\end{array}$ \\
\hline \multicolumn{4}{|c|}{ LDPE-A } \\
\hline Neat (unexposed) & $160 \pm 2$ & $17.7 \pm 0.2$ & $156.2 \pm 2.2$ \\
\hline UV1 (unexposed) & $133 \pm 2$ & $17.5 \pm 0.1$ & $140.6 \pm 3.4$ \\
\hline UV2 (unexposed) & $127 \pm 2$ & $16.8 \pm 0.3$ & $145.5 \pm 4.0$ \\
\hline Neat (1 month heat exposed) & $158 \pm 8$ & $16.6 \pm 0.5$ & $144.0 \pm 3.7$ \\
\hline UV1 (1 month heat exposed) & $243 \pm 13$ & $18.2 \pm 0.4$ & $152.8 \pm 4.0$ \\
\hline UV2 (1 month heat exposed) & $226 \pm 23$ & $17.5 \pm 0.4$ & $177.6 \pm 8.3$ \\
\hline Neat (2 months heat exposed) & $144 \pm 3$ & $16.8 \pm 0.2$ & $147.4 \pm 3.4$ \\
\hline UV1 (2 months heat exposed) & $242 \pm 7$ & $18.3 \pm 0.3$ & $166.1 \pm 0.5$ \\
\hline UV2 (2 months heat exposed) & $234 \pm 21$ & $17.8 \pm 1.3$ & $164.5 \pm 2.5$ \\
\hline Neat (3 months heat exposed) & $148 \pm 10$ & $16.4 \pm 0.9$ & $151.0 \pm 2.2$ \\
\hline UV1 (3 months heat exposed) & $209 \pm 9$ & $18.8 \pm 0.3$ & $166.2 \pm 7.5$ \\
\hline UV2 (3 months heat exposed) & $202 \pm 3$ & $19.0 \pm 0.7$ & $160.9 \pm 3.3$ \\
\hline Neat (4 months heat exposed) & $265 \pm 38$ & $18.3 \pm 0.4$ & $156.0 \pm 3.5$ \\
\hline UV1 (4 months heat exposed) & $237 \pm 13$ & $18.0 \pm 0.4$ & $172.1 \pm 4.8$ \\
\hline UV2 (4 months heat exposed) & $205 \pm 27$ & $18.1 \pm 0.3$ & $163.6 \pm 2.0$ \\
\hline Neat (6 months heat exposed) & $241 \pm 18$ & $17.7 \pm 0.3$ & $173.1 \pm 4.3$ \\
\hline UV1 (6 months heat exposed) & $213 \pm 24$ & $19.3 \pm 0.7$ & $177.5 \pm 5.4$ \\
\hline UV2 (6 months heat exposed) & $200 \pm 30$ & $18.2 \pm 0.2$ & $169.1 \pm 6.8$ \\
\hline Neat (8 months heat exposed) & $225 \pm 12$ & $17.1 \pm 2.1$ & $173.1 \pm 12.3$ \\
\hline UV1 ( 8 months heat exposed) & $223 \pm 9$ & $18.1 \pm 0.4$ & $174.6 \pm 6.1$ \\
\hline UV2 (8 months heat exposed) & $229 \pm 8$ & $17.5 \pm 0.3$ & $179.4 \pm 5.6$ \\
\hline Neat (10 months heat exposed) & $236 \pm 9$ & $17.7 \pm 0.6$ & $167.4 \pm 8.3$ \\
\hline UV1 (10 months heat exposed) & $234 \pm 5$ & $18.2 \pm 0.6$ & $177.1 \pm 16.5$ \\
\hline UV2 (10 months heat exposed) & $233 \pm 5$ & $17.4 \pm 0.9$ & $165.5 \pm 2.3$ \\
\hline Neat (12 months heat exposed) & $245 \pm 3$ & $16.8 \pm 0.1$ & $152.9 \pm 3.6$ \\
\hline UV1 (12 months heat exposed) & $241 \pm 11$ & $17.7 \pm 0.2$ & $174.8 \pm 15.0$ \\
\hline UV2 (12 months heat exposed) & $244 \pm 2$ & $17.5 \pm 0.3$ & $172.9 \pm 8.8$ \\
\hline
\end{tabular}

\begin{tabular}{|c|c|c|c|}
\hline Sample & $\begin{array}{c}E \\
\text { [MPa] }\end{array}$ & $\begin{array}{c}\sigma \\
{[\mathrm{MPa}]}\end{array}$ & $\begin{array}{c}\varepsilon \\
{[\%]} \\
\end{array}$ \\
\hline \multicolumn{4}{|c|}{ LDPE-T } \\
\hline Neat (unexposed) & $242 \pm 16$ & $18.4 \pm 0.9$ & $118.0 \pm 1.3$ \\
\hline UV1 (unexposed) & $205 \pm 33$ & $17.3 \pm 2.3$ & $152.0 \pm 8.0$ \\
\hline UV2 (unexposed) & $176 \pm 5$ & $18.1 \pm 0.3$ & $150.1 \pm 3.1$ \\
\hline Neat (1 month heat exposed) & $183 \pm 2$ & $17.7 \pm 0.3$ & $131.9 \pm 4.2$ \\
\hline UV1 (1 month heat exposed) & $293 \pm 36$ & $18.6 \pm 1.7$ & $151.6 \pm 6.6$ \\
\hline UV2 (1 month heat exposed) & $303 \pm 14$ & $18.7 \pm 0.5$ & $144.6 \pm 5.2$ \\
\hline Neat (2 months heat exposed) & $186 \pm 9$ & $17.5 \pm 1.0$ & $121.2 \pm 13.1$ \\
\hline UV1 (2 months heat exposed) & $304 \pm 41$ & $19.3 \pm 0.3$ & $149.5 \pm 1.4$ \\
\hline UV2 (2 months heat exposed) & $236 \pm 5$ & $18.9 \pm 0.4$ & $152.9 \pm 7.6$ \\
\hline Neat (3 months heat exposed) & $178 \pm 4$ & $17.6 \pm 0.3$ & $141.2 \pm 1.5$ \\
\hline UV1 (3 months heat exposed) & $241 \pm 12$ & $19.4 \pm 0.3$ & $152.4 \pm 6.4$ \\
\hline UV2 (3 months heat exposed) & $263 \pm 5$ & $18.0 \pm 0.1$ & $157.3 \pm 2.7$ \\
\hline Neat (4 months heat exposed) & $255 \pm 8$ & $17.3 \pm 0.1$ & $148.8 \pm 3.2$ \\
\hline UV1 (4 months heat exposed) & $253 \pm 42$ & $19.1 \pm 1.0$ & $164.2 \pm 5.3$ \\
\hline UV2 (4 months heat exposed) & $215 \pm 42$ & $18.2 \pm 0.5$ & $153.9 \pm 5.8$ \\
\hline Neat (6 months heat exposed) & $255 \pm 13$ & $17.4 \pm 0.1$ & $147.2 \pm 1.7$ \\
\hline UV1 (6 months heat exposed) & $245 \pm 40$ & $18.6 \pm 0.4$ & $165.7 \pm 2.8$ \\
\hline UV2 (6 months heat exposed) & $263 \pm 26$ & $18,0 \pm 0.3$ & $164.0 \pm 9.1$ \\
\hline Neat (10 months heat exposed) & $314 \pm 8$ & $18.5 \pm 0.2$ & $120.6 \pm 5.0$ \\
\hline UV1 (10 months heat exposed) & $309 \pm 12$ & $19.3 \pm 0.4$ & $139.5 \pm 2.4$ \\
\hline UV2 (10 months heat exposed) & $295 \pm 20$ & $18.9 \pm 0.2$ & $146.7 \pm 3.9$ \\
\hline Neat (12 months heat exposed) & $310 \pm 6$ & $18.4 \pm 0.1$ & $138.5 \pm 2.0$ \\
\hline UV1 (12 months heat exposed) & $326 \pm 3$ & $18.7 \pm 0.3$ & $147.1 \pm 3.4$ \\
\hline UV2 (12 months heat exposed) & $291 \pm 40$ & $18.7 \pm 0.1$ & $145.9 \pm 4.1$ \\
\hline
\end{tabular}


trend, the degradation was not found to be as severe as it was during UV exposure, since only low variations in the tensile strength and elongation at break were seen even for the neat polymers. For example, in the case of LDPE-T the tensile strength increased by $\sim 9 \%$ after 12 months, and the elongation was effectively the same. According to literature, the neat polymers should have shown different behavior in terms of tensile properties, i.e., increases in $\sigma$ and $E$ and a strong decrease in $\varepsilon$, underlining the brittle character of the material due to intense cross-linking occurring during heat aging [27]. A possible explanation for the opposite trend in our case is probably the fact that the neat polymers were pre-stabilized by the manufacturer with 1000 ppm of primary antioxidants, which obviously scavenged the formed free radicals formed during exposure to heat, thus protecting the polymer against heat.

However, Young's modulus was found to be a more sensitive property to monitor the heat-induced degradation. For the first 3 months, $E$ slightly decreased for neat LDPE-A (by 10\%) and for LDPE-T (by 26\%), with this trend being attributed to chain scission reactions. The more intense change in the case of LDPE-T was probably due to the already discussed steric factors. After the first three months, $E$ increased by $70 \%$ for LDPE-A and $74 \%$ for LDPE-T due to enhanced cross-linking. For all the stabilized grades, $E$ increased during the first month of exposure, probably due to annealing, after which it varies very little during the rest of the exposure. In the case of LDPE-A/ UV2, $E$ increased by only $20 \%$ for the time period of 3 to 12 months, and for LDPE-T/UV2 by $10 \%$.

\subsubsection{Impact testing}

When looking at the impact behavior of the unexposed materials (Table 6), it seems that in the case of LDPE-A, UV1 shows a slight decrease in impact strength, while UV2 shows the same value than that of the neat polymer, i.e. $\sim 19 \mathrm{~kJ} \cdot \mathrm{m}^{-2}$. This is in line with the increased tensile strength, i.e., $19.5 \mathrm{MPa}$ determined before, and proves that the UV1 formulation is more brittle. On the other hand, for the LDPE-T compounds, UV1 shows a $25 \%$ higher impact strength than the neat grade, while UV2 again shows the same value. There was also little difference between the values of neat LDPE-A and LDPE-T, i.e. $19.1 v s$. $17.3 \mathrm{~kJ} \cdot \mathrm{m}^{-2}$, with LDPE-A showing a more ductile character.

When looking at the impact behavior after UV exposure, the values for both neat LDPE-A and LDPE-T remained fairly constant up to $1000 \mathrm{~h} \mathrm{UV}$ exposure, but decreased significantly up to $2000 \mathrm{~h}$ UV exposure. This is in line with the $E$ increase of the neat polymers after the exposure to UV radiation. As with the other mechanical properties, there were no real changes in the impact strength of the stabilized samples for both polymers within experimental error. This again proves the effectiveness of the UV/heat stabilized formulations.

\subsection{Thermal analysis}

\subsubsection{Thermogravimetric analysis (TGA)}

The thermal decomposition behavior of the neat and UV-aged samples was investigated through TGA to determine their thermal stability. Table 7 summarizes the degradation temperatures of all the samples, while

Table 6. Impact testing results for all the investigated LDPE-A and LDPE-T samples.

\begin{tabular}{|c|c|c|c|}
\hline Sample & $\begin{array}{c}\text { Izod impact strength } \\
{\left[\mathrm{kJ} \cdot \mathrm{m}^{-2}\right]}\end{array}$ & Sample & $\begin{array}{c}\text { Izod impact strength } \\
{\left[\mathrm{kJ} \cdot \mathrm{m}^{-2}\right]}\end{array}$ \\
\hline Neat LDPE-A (unexposed) & $19.1 \pm 4.9$ & Neat LDPE-T (unexposed) & $17.3 \pm 2.0$ \\
\hline LDPE-A/UV1 (unexposed) & $15.9 \pm 0.6$ & LDPE-T/UV1 (unexposed) & $21.7 \pm 3.3$ \\
\hline LDPE-A/UV2 (unexposed) & $19.0 \pm 2.4$ & LDPE-T/UV2 (unexposed) & $17.1 \pm 2.1$ \\
\hline Neat LDPE-A (1000 h UV exposed) & $21.3 \pm 2.1$ & Neat LDPE-T (1000 h UV exposed) & $17.9 \pm 3.2$ \\
\hline LDPE-A/UV1 (1000 h UV exposed) & $17.6 \pm 2.5$ & LDPE-T/UV1 (1000 h UV exposed) & $22.6 \pm 2.3$ \\
\hline LDPE-A/UV2 (1000 h UV exposed) & $18.9 \pm 2.1$ & LDPE-T/UV2 (1000 h UV exposed) & $21.2 \pm 2.0$ \\
\hline Neat LDPE-A (1500 h UV exposed) & $16.5 \pm 1.4$ & Neat LDPE-T (1500 h UV exposed) & $13.7 \pm 0.9$ \\
\hline LDPE-A/UV1 (1500 h UV exposed) & $18.8 \pm 1.9$ & LDPE-T/UV1 (1500 h UV exposed) & $19.7 \pm 1.7$ \\
\hline LDPE-A/UV2 (1500 h UV exposed) & $21.1 \pm 2.9$ & LDPE-T/UV2 (1500 h UV exposed) & $21.2 \pm 3.8$ \\
\hline Neat LDPE-A (2000 h UV exposed) & $10.3 \pm 1.6$ & Neat LDPE-T (2000 h UV exposed) & $10.2 \pm 1.4$ \\
\hline LDPE-A/UV1 (2000 h UV exposed) & $17.1 \pm 1.5$ & LDPE-T/UV1 (2000 h UV exposed) & $21.5 \pm 1.4$ \\
\hline LDPE-A/UV2 (2000 h UV exposed) & $19.7 \pm 4.1$ & LDPE-T/UV2 (2000 h UV exposed) & $19.4 \pm 1.2$ \\
\hline
\end{tabular}


Table 7. TGA onset of mass loss $\left(T_{\mathrm{d}, 5 \%}\right)$ and maximum mass loss rate $\left(T_{\mathrm{d}, \max }\right)$ temperatures for all the investigated samples.

\begin{tabular}{|c|c|c|c|c|c|}
\hline LDPE-A & $\begin{array}{l}T_{\mathrm{d}, 5 \%}{ }^{\circ} \\
{\left[{ }^{\circ} \mathbf{C}\right]}\end{array}$ & $\begin{array}{c}T_{\mathrm{d}, \max } \\
{\left[{ }^{\circ} \mathrm{C}\right]}\end{array}$ & LDPE-T & $\begin{array}{c}T_{\mathrm{d}, 5 \%}{ } \\
{\left[{ }^{\circ} \mathrm{C}\right]}\end{array}$ & $\begin{array}{c}T_{\mathrm{d}, \text { max }} \\
{\left[{ }^{\circ} \mathbf{C}\right]}\end{array}$ \\
\hline Neat (unexposed) & 422.8 & 478.7 & Neat (unexposed) & 426.2 & 487.0 \\
\hline UV1 (unexposed) & 426.7 & 480.1 & UV1 (unexposed) & 399.0 & 477.1 \\
\hline UV2 (unexposed) & 432.0 & 486.2 & UV2 (unexposed) & 443.4 & 495.6 \\
\hline Neat (1000 h UV) & 409.0 & 472.0 & Neat (1000 h UV) & 424.7 & 490.9 \\
\hline UV1 (1000 h UV) & 438.7 & 484.7 & UV1 (1000 h UV) & 416.5 & 480.4 \\
\hline UV2 (1000 h UV) & 436.9 & 490.5 & UV2 (1000 h UV) & 424.7 & 487.4 \\
\hline Neat (1500 h UV) & 403.4 & 485.6 & Neat (1500 h UV) & 414.6 & 490.4 \\
\hline UV1 (1500 h UV) & 419.5 & 480.2 & UV1 (1500 h UV) & 403.8 & 478.9 \\
\hline UV2 (1500 h UV) & 435.4 & 480.6 & UV2 (1500 h UV) & 412.4 & 482.3 \\
\hline Neat (2000 h UV) & 381.0 & 482.6 & Neat (2000 h UV) & 396.9 & 495.3 \\
\hline UV1 (2000 h UV) & 421.9 & 473.8 & UV1 (2000 h UV) & 405.8 & 480.4 \\
\hline UV2 (2000 h UV) & 431.2 & 480.8 & UV2 (2000 h UV) & 412.1 & 479.2 \\
\hline
\end{tabular}

in the relevant TGA curves (not shown) all the samples showed a one-step decomposition.

For the unexposed polymers, the onset of degradation was found at 423 and $426^{\circ} \mathrm{C}$ respectively for LDPE-A and LDPE-T, with a maximum rate of mass loss at 479 and $487^{\circ} \mathrm{C}$. The lower $T_{\mathrm{d}}$ value for LDPE-A can be attributed to its higher branching degree, which causes this polymer to have more thermally unstable tertiary carbons. Similarly, the temperatures at maximum mass loss rate for the UV exposed neat samples showed higher values for LDPE-T in the range of 491 to $495^{\circ} \mathrm{C}$ compared to those of LDPE-A, that are in the range of 472 to $482^{\circ} \mathrm{C}$.

The effect of photo-oxidation on the neat polymers can be seen mainly in the changes in the $T_{\mathrm{d}, 5 \%}$ values. However, it should be taken into account that the thermal properties reflect the structures of the surface and the bulk of the polymers, and not only those of the surface, which is mainly deteriorated by UV exposure. The $T_{\mathrm{d}, 5 \%}$ values decreased for both neat LDPE-A (from 423 to $381{ }^{\circ} \mathrm{C}$ ) and LDPE-T (from 426 to $397^{\circ} \mathrm{C}$ ) proportionally to UV exposure time, while in the stabilized grades there is even an increase in the onset temperature of degradation: LDPE-A/UV2 seems to be the best formulation in terms of thermal stability as it maintained good stability even after long exposure periods. On the other hand, LDPE-T/UV2 was the least promising formulation in terms of thermal stability, because its thermal stability decreased significantly after only $1000 \mathrm{~h}$ of accelerated UV aging. Generally, the UV/heat stabilized LDPE-A samples were thermally more stable, and the thermal stability was less influenced by UV exposure than the stabilized LDPE-T samples, which is contrary to our observation for the neat polymers. This implies that the thermal stability of LDPE-A was enhanced more by the addition of the UV-stabilizers.

\subsubsection{Differential scanning calorimetry (DSC)}

DSC analysis was performed to follow the melting behavior and crystallinity of the neat and UV/heat stabilized LDPEs before and after different periods of UV exposure. The DSC first heating and cooling curves of all the investigated samples are shown in Figure 3 and Table 8 . We will discuss the first heating results for all the samples, because we are interested in the initial influence of UV exposure on the melting behavior and crystallinity of the different samples, taking into account that these properties reflect the structures of the surfaces and bulk of the materials. The first heating curves of the neat LDPEs (Figure 3a, 3d) show a slight appearance of a lower temperature shoulder for the UV exposed samples, which was not observed for the unexposed samples. This could indicate the formation of a smaller crystal fraction as a result of UV initiated degradation via scission reactions and re-crystallization. For the UV1 and UV2 stabilized samples of both LDPEs, the first heating curves all show the development of a much more resolved lower temperature peak shoulder after accelerated UV exposure. This could be the result of the formation of smaller crystals around the UV stabilization additives, that acted as nucleation centers in the two LDPEs.

The melting temperatures of the main fractions of all the samples were found very similar within experimental error (Table 8). However, the melting enthalpies increased significantly after UV exposure, although there were no or insignificant increases for 

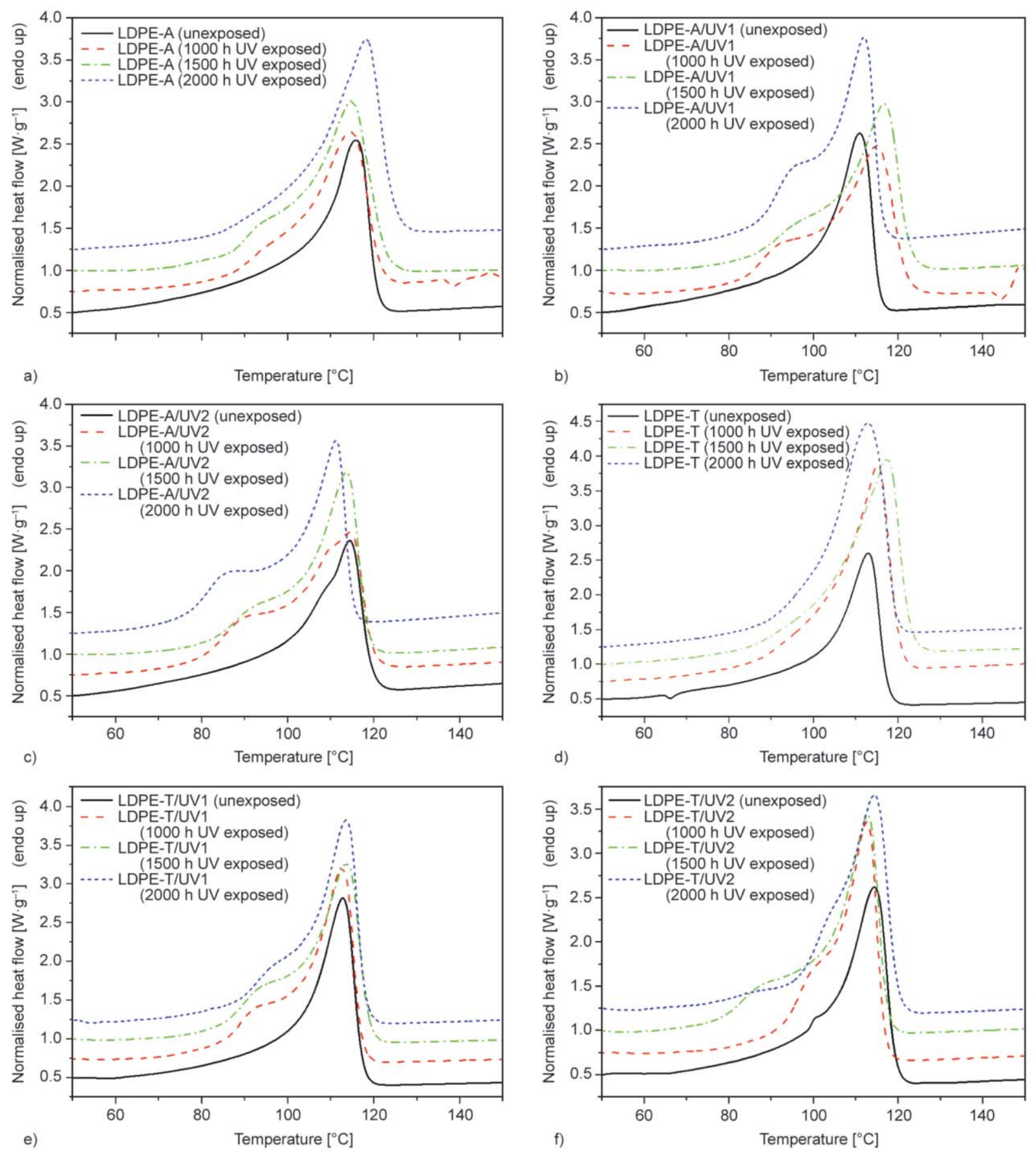

Figure 3. DSC first heating curves in nitrogen atmosphere of (a) neat LDPE-A, (b) LDPE-A/UV1, (c) LDPE-A/UV2, (d) neat LDPE-T, (e) LDPE-T/UV1, and (f) LDPE-T/UV2 before and after UV exposure for different time periods.

the UV1 and UV2 formulated samples that were UV exposed for longer than $1000 \mathrm{~h}$. This indicates increased crystallinities as a result of degradative chain scission and re-crystallization of the neat samples during the overall course of exposure. It is not clear why similar increases (at least initially) were observed in the enthalpy values (crystallinities) of the UV1, and UV2 stabilized samples up to $1000 \mathrm{~h}$ accelerated UV exposure, but as in the case of heat-aging, this can be attributed to a small extent of crosslinking and some annealing. Generally, the differences between the corresponding enthalpies for the LDPE-A and LDPE-T based samples were within experimental error (Table 8).

The crystallization temperatures in Table 8 show very interesting trends. For neat LDPE-A, the UV exposed samples show observably lower crystallization temperatures than the unexposed neat LDPE-A, while the same is not observed for any of the stabilized LDPE-A samples, and also not for the neat and 
Table 8. DSC melting and crystallization temperatures and enthalpies of LDPE-A and its UV/heat stabilization formulations after different times of UV exposure.

\begin{tabular}{|c|c|c|c|c|c|c|}
\hline \multirow[t]{2}{*}{ Sample } & \multicolumn{2}{|c|}{ First heating } & \multicolumn{2}{|c|}{ Cooling } & \multicolumn{2}{|c|}{ Second heating } \\
\hline & $\begin{array}{c}\boldsymbol{T}_{\mathbf{m}} \\
{\left[{ }^{\circ} \mathbf{C}\right]}\end{array}$ & $\begin{array}{c}\Delta \boldsymbol{H}_{\mathbf{m}} \\
{\left[\mathbf{J} \cdot \mathbf{g}^{-1}\right]}\end{array}$ & $\begin{array}{c}T_{\mathbf{c}} \\
{\left[{ }^{\circ} \mathbf{C}\right]}\end{array}$ & $\begin{array}{c}\Delta \boldsymbol{H}_{\mathrm{c}} \\
{\left[\mathbf{J} \cdot \mathbf{g}^{-1}\right]}\end{array}$ & $\begin{array}{c}\boldsymbol{T}_{\mathbf{m}} \\
{\left[{ }^{\circ} \mathbf{C}\right]}\end{array}$ & $\begin{array}{c}\Delta \boldsymbol{H}_{\mathrm{m}} \\
{\left[\mathrm{J} \cdot \mathrm{g}^{-1}\right]}\end{array}$ \\
\hline \multicolumn{7}{|c|}{ LDPE-A } \\
\hline Neat (unexposed) & 116.6 & 62.6 & 95.8 & -78.1 & 113.3 & 67.0 \\
\hline UV1 (unexposed) & 111.1 & 60.0 & 94.3 & -70.2 & 111.1 & 55.9 \\
\hline UV2 (unexposed) & 115.7 & 60.6 & 92.8 & -74.5 & 112.6 & 58.2 \\
\hline Neat (1000 h UV) & 114.8 & 87.6 & 990.0 & -72.7 & 113.1 & 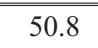 \\
\hline UV1 (1000 h UV) & 115.2 & 89.9 & 92.7 & -71.8 & 113.9 & 59.5 \\
\hline UV2 (1000 h UV) & 114.4 & 92.6 & 92.4 & -73.9 & 113.5 & 52.6 \\
\hline Neat (1500 h UV) & 114.8 & 107.4 & 89.6 & -76.2 & 113.8 & 59.4 \\
\hline UV1 (1500 h UV) & 116.8 & 90.1 & 92.7 & -71.8 & 115.1 & 56.0 \\
\hline UV2 (1500 h UV) & 113.8 & 86.0 & 93.1 & -74.3 & 112.2 & 56.9 \\
\hline Neat (2000 h UV) & 118.4 & 108.1 & 90.7 & -81.6 & 115.7 & 66.9 \\
\hline UV1 (2000 h UV) & 112.1 & 101.5 & 94.1 & -73.2 & 111.2 & 65.7 \\
\hline UV2 (2000 h UV) & 111.3 & 97.4 & 94.4 & -71.3 & 110.5 & 52.7 \\
\hline \multicolumn{7}{|c|}{ LDPE-T } \\
\hline Neat (unexposed) & 111.3 & 60.1 & 94.0 & -78.9 & 113.0 & 59.6 \\
\hline UV1 (unexposed) & 113.1 & 65.6 & 94.6 & -78.6 & 112.5 & 59.0 \\
\hline UV2 (unexposed) & 113.8 & 69.6 & 94.1 & -78.0 & 113.5 & 64.5 \\
\hline Neat (1000 h UV) & 115.4 & 110.6 & 91.5 & -86.2 & 112.6 & 69.1 \\
\hline UV1 (1000 h UV) & 112.9 & 93.2 & 94.6 & -79.2 & 112.6 & 60.5 \\
\hline UV2 (1000 h UV) & 112.8 & 96.2 & 94.7 & -78.6 & 112.7 & 60.1 \\
\hline Neat (1500 h UV) & 117.7 & 115.2 & 93.0 & -90.8 & 114.6 & 71.3 \\
\hline UV1 (1500 h UV) & 113.8 & 99.9 & 93.7 & -78.5 & 113.9 & 61.0 \\
\hline UV2 (1500 h UV) & 113.0 & 92.6 & 94.6 & -79.4 & 112.8 & 61.7 \\
\hline Neat (2000 h UV) & 112.9 & 127.0 & 94.5 & -97.4 & 111.7 & 80.4 \\
\hline UV1 (2000 h UV) & 113.8 & 99.7 & 94.5 & -78.4 & 113.7 & 62.7 \\
\hline UV2 (2000 h UV) & 114.5 & 97.7 & 94.1 & -78.1 & 114.0 & 60.8 \\
\hline
\end{tabular}

stabilized LDPE-T samples. This is a very clear difference between LDPE-A and LDPE-T, and can be related to the differences in long-chain branching (LCB) between these two polymers. LDPE-A, which has more LCB, probably has longer chains after UV initiated degradation, that needs lower temperatures for effective crystallization. This is further supported by the much broader crystallization peaks of the UV exposed neat LDPE-A samples (DSC cooling curves, not presented in this paper).

\subsection{Fourier-transform infrared (FTIR) spectroscopy}

In photochemical and thermal oxidation of polymers, it is well-known that some oxidized groups are generated, and it is common practice to determine the change of these groups during the oxidation of the polymers. In particular, carbonyl groups are an indication of chemical changes occurring in polyolefins during oxidative degradation [28]. Therefore, FTIR analysis of all the samples was performed in order to prove that oxidative degradation only occurred in the neat LDPE samples, and not in the UV1 and UV2 stabilized samples. Figure 4 clearly shows that there was no formation of carbonyl groups in the UV stabilized samples, while the neat LDPE-A and LDPE-T clearly show the formation of carbonyl groups after only $1000 \mathrm{~h}$ of accelerated UV exposure. The carbonyl indices reported in Table 9 are very similar for LDPE-A and LDPE-T, which indicates that the differences in polymer structure had little influence on the formation of carbonyl groups during the oxidative degradation process.

\section{Conclusions}

The morphology, thermal and mechanical properties of two different UV absorbers/HALS formulations incorporated in two different low-density polyethylene grades with different structures were investigated using SEM, GPC, DSC, TGA, FTIR, as well as 

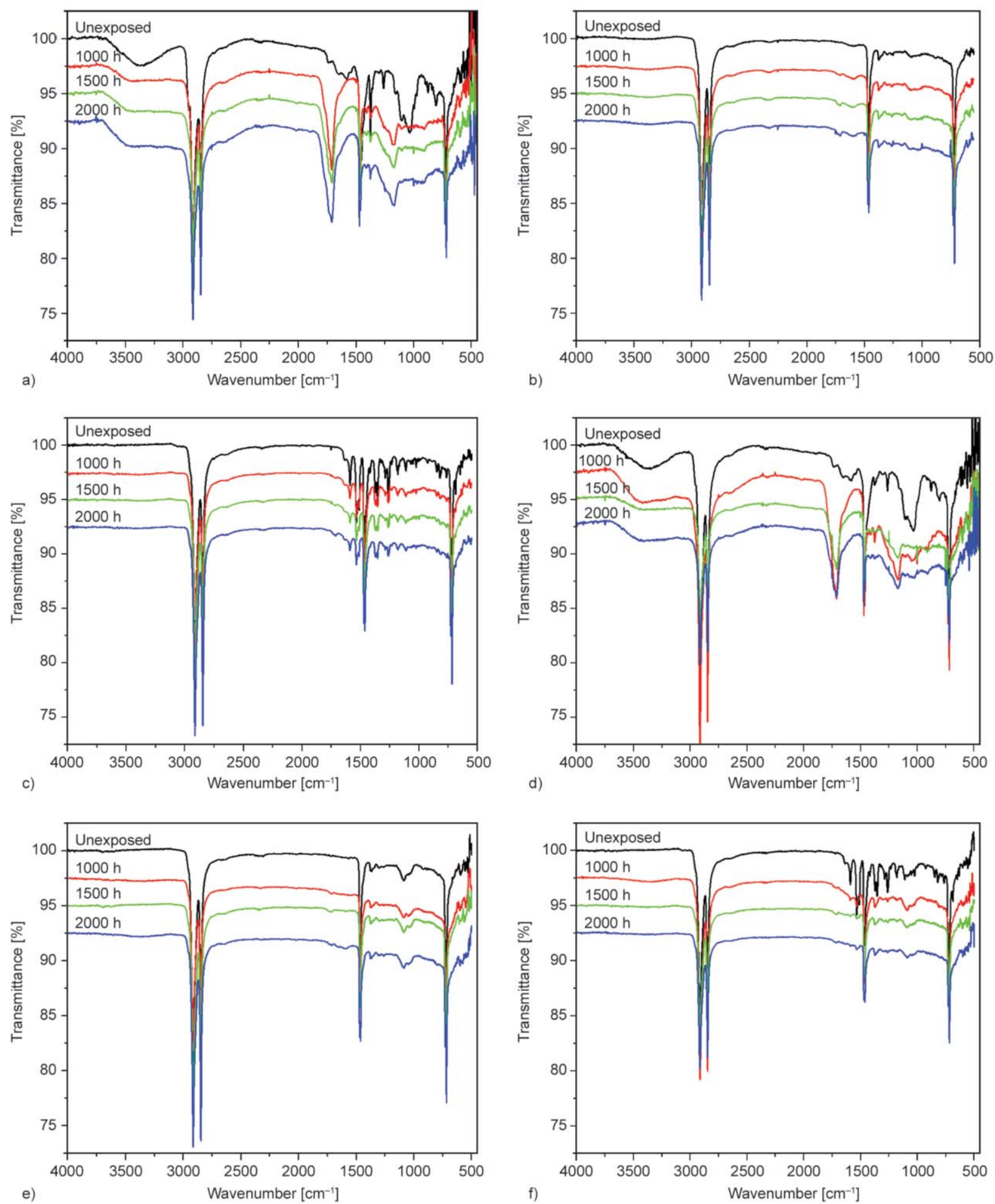

Figure 4. FTIR spectra of (a) LDPE-A, (b) LDPE-A/UV1, (c) LDPE-A/UV2, (d) LDPE-T, (e) LDPE-T/UV1, and (f) LDPE-T/UV2 before UV exposure and after different times of UV exposure. The peaks in these spectra were used for the calculation of the carbonyl index values in Table 9 of the paper.

tensile and impact testing, after exposing them to artificial UV/heat conditions through accelerated (artificial) weathering and thermal aging tests. The SEM micrographs revealed a significant degradation for neat LDPE-A and LDPE-T after $2000 \mathrm{~h} \mathrm{UV}$ exposure, whereas almost no cracks were observed for all the stabilized samples. The GPC results, along with changes in the tensile properties (increase in Young's modulus, decrease in elongation at break), indicate a chain scission/branching mechanism resulting in crosslinking for both LDPEs, while UV aging was found more severe in the comb-like LDPE-T produced 
Table 9. Carbonyl index values of all the investigated samples before and after different periods of accelerated UV exposure.

\begin{tabular}{|c|c|c|c|}
\hline Sample & Carbonyl indext & Sample & Carbonyl index \\
\hline LDPE-A (unexposed) & - & LDPE-T (unexposed) & - \\
\hline LDPE-A/UV1 (unexposed) & - & LDPE-T/UV1 (unexposed) & - \\
\hline LDPE-A/UV2 (unexposed) & - & LDPE-T/UV2 (unexposed) & - \\
\hline LDPE-A (1000 h UV) & 0.88 & LDPE-T (1000 h UV) & 0.85 \\
\hline LDPE-A/UV1 (1000 h UV) & - & LDPE-T/UV1 (1000 h UV) & - \\
\hline LDPE-A/UV2 (1000 h UV) & - & LDPE-T/UV2 (1000 h UV) & - \\
\hline LDPE-A (1500 h UV) & 0.85 & LDPE-T (1500 h UV) & 0.79 \\
\hline LDPE-A/UV1 (1500 h UV) & - & LDPE-T/UV1 (1500 h UV) & - \\
\hline LDPE-A/UV2 (1500 h UV) & - & LDPE-T/UV2 (1500 h UV) & - \\
\hline LDPE-A (2000 h UV) & 0.93 & LDPE-T (2000 h UV) & 0.87 \\
\hline LDPE-A/UV1 (2000 h UV) & - & LDPE-T/UV1 (2000 h UV) & - \\
\hline LDPE-A/UV2 (2000 h UV) & - & LDPE-T/UV2 (2000 h UV) & - \\
\hline
\end{tabular}

by tubular process technology, and this was correlated with steric factors. Regarding the applied stabilization, the system of an oligomeric or high molecular weight HALS with a UV absorber of benzophenone or hydroxyphenyl-triazine type at a total content of $0.2 \mathrm{wt} \%$ did not severely change the initial mechanical and thermal properties of the two grades. The induced stabilization was confirmed by maintaining the tensile and impact properties as well as the onset of polymer thermal degradation after different periods of UV exposure, while no carbonyl groups were formed. The efficiency of the additives was proven for both types of LDPE, irrespective to their molecular structure, while some properties changed differently depending on the LDPE grade as a result of UV- and/or heat aging.

\section{Acknowledgements}

This publication was made possible by the NPRP award (NPRP 9-161-1-030) from the Qatar National Research Fund (a member of The Qatar Foundation). We are also grateful to BASF and Sabo for supplying the additives at no cost. The statements made herein are solely the responsibility of the author(s).

\section{References}

[1] Ronca S.: Polyethylene. in 'Brydson's plastics materials’ (ed.: Gilbert M.) Elsevier, Amsterdam, 247-278 (2017).

https://doi.org/10.1016/B978-0-323-35824-8.00010-4

[2] Grigoriadou I., Paraskevopoulos K. M., Chrissafis K., Pavlidou E., Stamkopoulos T-G., Bikiaris D.: Effect of different nanoparticles on HDPE UV stability. Polymer Degradation and Stability, 96, 151-163 (2011).

https://doi.org/10.1016/j.polymdegradstab.2010.10.001
[3] Lu M., Liu P., Zhang S., Yuan W., Ding S., Wang F., Ding Y., Yang M.: Anti-aging behavior of amino-containing co-condensed nanosilica in polyethylene. Polymer Degradation and Stability, 154, 137-148 (2018). https://doi.org/10.1016/j.polymdegradstab.2018.05.028

[4] Feldman D.: Polymer weathering: Photo-oxidation. Journal of Polymers and the Environment, 10, 163-173 (2002).

https://doi.org/10.1023/A:1021148205366

[5] Al-Salem S. M.: Influential parameters on natural weathering under harsh climatic conditions of mechanically recycled plastic film specimens. Journal of Environmental Management, 230, 355-365 (2019). https://doi.org/10.1016/j.jenvman.2018.09.044

[6] Julienne F., Lagarde F., Delorme N.: Influence of the crystalline structure on the fragmentation of weathered polyolefines. Polymer Degradation and Stability, 170, 109012/1-09012/8 (2019). https://doi.org/10.1016/j.polymdegradstab.2019.109012

[7] Ambrogi V., Carfagna C., Cerruti P., Marturano V.: Additives in polymers. in 'Modification of polymer properties’ (eds. Jasso-Gastinel C., Kenny J.) Elsevier, Amsterdam, 87-108 (2017).

https://doi.org/10.1016/B978-0-323-44353-1.00004-X

[8] Jacob N. C., Dhib R.: Nonlinear MPC of a multi-zone multi-feed LDPE autoclave reactor. Journal of Industrial and Engineering Chemistry, 18, 1781-1795 (2012). https://doi.org/10.1016/j.jiec.2012.04.001

[9] Pandey G. C., Singh B. P., Kulshreshtha V.: Morphological characterization of autoclave and tubular LDPE by high temperature IR spectroscopy. Polymer Testing, 9, 341-351 (1990).

https://doi.org/10.1016/0142-9418(90)90005-X

[10] Luyt A. S., Malik S. S., Gasmi S. A., Porfyris A., Andronopoulou A., Korres D., Vouyiouka S., Grosshauser M., Pfaendner R. Brüll R., Papaspyrides C.: Halogenfree flame-retardant compounds. Thermal decomposition and flammability behavior for alternative polyethylene grades. Polymers, 11, 1479/1-1479/17 (2019). https://doi.org/10.3390/polym11091479 
[11] Lee H-J., Yeo Y-K., Chang J-Y.: Modeling of industrial high pressure autoclave polyethylene reactor including decomposition phenomena. Korean Journal of Chemical Engineering, 17, 223-229 (2000).

https://doi.org/10.1007/BF02707147

[12] Kuhn R., Krömer H.: Structures and properties of different low density polyethylenes. Colloid and Polymer Science, 260, 1083-1092 (1982).

https://doi.org/10.1007/BF01411226

[13] Zimmering B. L., Kumar A., Boccara A. C., Pandey G. C.: Photophysical and photodecomposition studies on polyethylenes: A novel application of gas-phase mirage-effect spectroscopy. Journal of Applied Polymer Science, 69, 1875-1883 (1998).

https://doi.org/10.1002/(SICI)10974628(19980829)69:9<1875::AID-APP23>3.0.CO;2-J

[14] Basfar A. A., Idriss Ali K. M.: Natural weathering test for films of various formulations of low density polyethylene (LDPE) and linear low density polyethylene (LLDPE). Polymer Degradation and Stability, 91, 437 443 (2006).

https://doi.org/10.1016/j.polymdegradstab.2004.11.027

[15] Al-Salem S. M.: Influence of natural and accelerated weathering on various formulations of linear low density polyethylene (LLDPE) films. Materials and Design, 30, 1729-1736 (2009).

https://doi.org/10.1016/j.matdes.2008.07.049

[16] Scoponi M., Cimmino S., Kaci M.: Photo-stabilisation mechanism under natural weathering and accelerated photo-oxidative conditions of LDPE films for agricultural applications. Polymer, 41, 7969-7980 (2000). https://doi.org/10.1016/S0032-3861(00)00160-9

[17] Cristofoli K., Brandalise R. N., Zeni M.: Photostabilized LDPE films with UV absorber and HALS as protection against the light for rosé sparkling wine. Journal of Food Processing and Technology, 3, 1000166/11000166/7 (2012).

https://doi.org/10.4172/2157-7110.1000166

[18] Poveda P. N. S., Magalhães Viana H., de Andrade Silva L. G.: Behavior of linear low density polyethylene films under UV ageing for agricultural application. in 'Characterization of minerals, metals, and materials' (eds.: Carpenter J. S., Bai C., Escobedo J. P., Hwang J-Y., Ikhmayies S., Li B., Li J., Monteiro S. N., Peng Z., Zhang M.) Wiley, New York, 253-258 (2015).

https://doi.org/10.1002/9781119093404.ch31
[19] Wypych G.: Handbook of UV degradation and stabilization. ChemTec, Toronto (2015).

[20] Peña J. M., Allen N. S., Edge M., Liauw C. M., Valange B.: Studies of synergism between carbon black and stabilisers in LDPE photodegradation. Polymer Degradation and Stability, 72, 259-270 (2001). https://doi.org/10.1016/S0141-3910(01)00033-7

[21] Gijsman P.: A review on the mechanism of action and applicability of hindered amine stabilizers. Polymer Degradation and Stability, 145, 2-10 (2017). https://doi.org/10.1016/j.polymdegradstab.2017.05.012

[22] Focke W. W., Mashele R. P., Nhlapo N. S.: Stabilization of low density polyethylene films containing metal stearates as photodegradants. Journal of Vinyl and Additives Technology, 17, 121-27 (2011). https://doi.org/10.1002/vnl.20248

[23] Hsu Y-C., Weir M. P., Truss R. W., Garvey C. J., Nicholson T. M., Halley P. J.: A fundamental study on photo-oxidative degradation of linear low density polyethylene films at embrittlement. Polymer, 53, 23852393 (2012). https://doi.org/10.1016/j.polymer.2012.03.044

[24] Simpson D. M., Vaughan G. A.: Ethylene polymers, LLDPE. in 'Encyclopedia of polymer science and technology' (ed.: Mark H. F.) Wiley, Hoboken, 441-482 (2001). https://doi.org/10.1002/0471440264.pst122

[25] Georgousopoulou I-N., Vouyiouka S., Dole P., Papaspyrides C.: Thermo-mechanical degradation and stabilization of poly(butylene succinate). Polymer Degradation and Stability, 128, 182-192 (2016). https://doi.org/10.1016/j.polymdegradstab.2016.03.012

[26] Maraschin N.: Ethylene polymers, LDPE. in 'Encyclopedia of polymer science and technology' (ed.: Mark H. F.) Wiley, Hoboken, 412-441 (2001). https://doi.org/10.1002/0471440264.pst121

[27] Kartalis C. N., Papaspyrides C. D., Pfaendner R., Hoffmann K., Herbst H.: Recycled and restabilized HDPE bottle crates: Retention of critical properties after heat aging. Polymer Engineering and Science, 41, 771-781 (2001).

https://doi.org/10.1002/pen.10774

[28] Mlinac Misăk M., Ranogajec F., Fleš D., Jovanović D.: Artificial ageing of low density polyethylene film containing chemically bound UV - stabilizer. Die Angewandte Makromolekulare Chemie, 137, 261-268 (1985). https://doi.org/10.1002/apmc.1985.051370120 